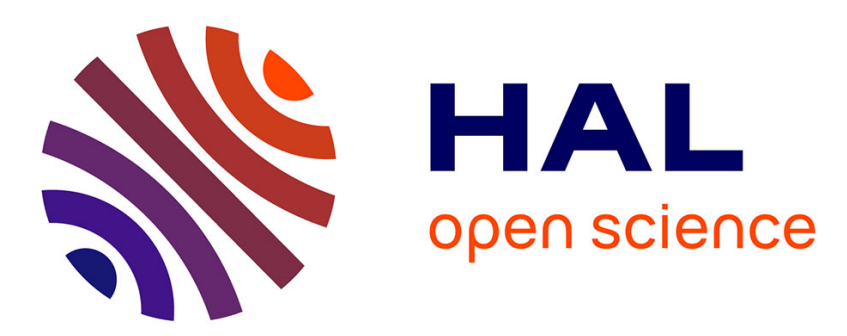

\title{
Gas-Phase Oxidation of Methyl-10-undecenoate in a Jet-Stirred Reactor
}

Xiangzan Meng, Olivier Herbinet, Lucie Coniglio, Tianyou Wang, Frederique Battin-Leclerc

\section{- To cite this version:}

Xiangzan Meng, Olivier Herbinet, Lucie Coniglio, Tianyou Wang, Frederique Battin-Leclerc. GasPhase Oxidation of Methyl-10-undecenoate in a Jet-Stirred Reactor. International Journal of Chemical Kinetics, 2017, 49 (10), pp.711-728. 10.1002/kin.21109 . hal-01669135

\section{HAL Id: hal-01669135 https://hal.science/hal-01669135}

Submitted on 20 Dec 2017

HAL is a multi-disciplinary open access archive for the deposit and dissemination of scientific research documents, whether they are published or not. The documents may come from teaching and research institutions in France or abroad, or from public or private research centers.
L'archive ouverte pluridisciplinaire HAL, est destinée au dépôt et à la diffusion de documents scientifiques de niveau recherche, publiés ou non, émanant des établissements d'enseignement et de recherche français ou étrangers, des laboratoires publics ou privés. 


\title{
GAS-PHASE OXIDATION OF METHYL-10-UNDECENOATE IN A JET-STIRRED \\ REACTOR
}

\author{
Xiangzan Meng ${ }^{1,2}$, Olivier Herbinet ${ }^{1}$, Lucie Coniglio ${ }^{1}$, Tianyou Wang $^{2}$, \\ Frédérique Battin-Leclerc ${ }^{1 *}$ \\ ${ }^{1}$ Laboratoire Réactions et Génie des Procédés, CNRS, Université de Lorraine, Nancy, France \\ ${ }^{2}$ State Key Laboratory of Engines, Tianjin University, Tianjin 300072, China
}

\begin{abstract}
To better understand the chemistry of biodiesel surrogates, the gas-phase oxidation of a $\mathrm{C}_{12}$ unsaturated methyl ester, methyl-10-undecenoate, has been studied in a jet-stirred reactor in the temperature range $500-1100 \mathrm{~K}$. These experiments were performed using neat fuel synthetized in the laboratory, with an initial fuel mole fraction set as 0.0021 , at quasiatmospheric pressure $(1.07 \mathrm{bar})$, at a residence time of $1.5 \mathrm{~s}$ with dilute mixtures in helium of equivalence ratios of $0.5,1.0$, and 2.0. The maximum obtained conversion was shown to be more than twice lower than that of methyl decanoate under the same conditions. This difference cannot be reproduced by the only published model for an unsaturated ester with a close number of carbon atoms (methyl-9-decenoate). A large range of products were quantified in addition to common oxidation products: saturated and unsaturated aldehydes, saturated and unsaturated methyl esters with a second carbonyl function, $\mathrm{C}_{2}-\mathrm{C}_{10}$ alkenes, $\mathrm{C}_{4}-$ $\mathrm{C}_{10}$ dienes, $\mathrm{C}_{4}-\mathrm{C}_{10}$ unsaturated methyl esters, $\mathrm{C}_{8}-\mathrm{C}_{9}$ saturated methyl esters, and saturated, unsaturated, and hydroxyl methyl esters involving a cyclic ether. Pathways of formation for the products specific to unsaturated ester oxidation were proposed and possible model improvements were discussed.
\end{abstract}

\footnotetext{
* Corresponding author. Frédérique Battin-Leclerc: E-mail: frederique.battin-leclerc@ univ-lorraine.fr, Phone: +33 372743819
} 
KEYWORDS: Methyl-10-undecenoate; Low temperature oxidation; Jet-stirred reactor.

\section{I/ INTRODUCTION}

Biodiesel, the renewable energy source used in compression-ignition engines, is composed of fatty acid methyl esters produced from vegetable oil or animal fat through transesterification [1]. While the composition in methyl esters depends on the parent feedstock, biodiesel mainly involves $\mathrm{C}_{16}-\mathrm{C}_{20}$ unsaturated compounds [1]. Autoignition delay times [2, 3] were measured for $\mathrm{C}_{19}$ unsaturated methyl esters using aerosol shock tubes. Studies of the combustion or oxidation of neat unsaturated esters including analyses of sooting tendency [4] or reaction product [5-7] were only made for reactant containing up to 7 atoms of carbons, except from the studies of Fridlyand et al. [8] and Feng et al. [9]. In the shock tube study of [8], the oxidation of methyl-trans-2-nonenoate and methyl-trans-3-nonenoate was investigated at high pressures $(\mathrm{P}=3.8-6.2 \mathrm{MPa})$ and temperatures $(\mathrm{T}=850-1500 \mathrm{~K})$ with a gas chromatographic quantification of carbon oxides and $\mathrm{C}_{1}-\mathrm{C}_{4}$ hydrocarbons. In the opposed-jet configuration flame work of [9], NO formation was followed using a chemiluminescence analyzer during the combustion at atmospheric pressure of $15 \mathrm{C}_{2}-\mathrm{C}_{12}$ methyl or ethyl esters including methyl10-undecenoate.

It is of particular interest to have experimental data about the oxidation of heavier unsaturated methyl esters with product analyses to assess the effect of biodiesel on engine emissions which have been shown to be potentially notable [10]. Due to experimental difficulties induced by their low vapor pressure, such oxidation studies were only performed using blends in order to favor vaporization. The oxidation of rapeseed methyl esters (RME) was studied by Dagaut et al. [11] in a jet-stirred reactor (JSR) at temperatures between 800 and $1400 \mathrm{~K}$. The team of Dagaut also investigated the oxidation of RME blended with kerosene [12] or diesel 
[13] under similar conditions. The JSR oxidation of methyl oleate in blend with $n$-decane was the subject of a study by Bax et al. [14]. Rodriguez et al. [15] were interested in the JSR oxidation of methyl oleate and methyl linoleate in blend with benzene. In these last two studies, experiments were carried out in a temperature range from 500 to $1050 \mathrm{~K}$, including the negative temperature coefficient zone. In all the JSR studies, reaction products were analyzed using gas-chromatography. A detailed kinetic model was proposed by Herbinet et al. [16] for the oxidation of a blend of methyl decanoate, methyl-5-decenoate and methyl-9decenoate as a blend surrogate of representative of biodiesel fuel. While this model has been widely accepted and reduced to be used in engine modeling (e.g. [17]), the comparisons of the obtained simulations with the experimental data of Dagaut et al. [11] for RME showed notable discrepancies.

The purpose of the present study is to present new experimental results about the JSR oxidation of a neat unsaturated ester of intermediate size in a temperature range from 500 to $1050 \mathrm{~K}$, including the negative temperature coefficient zone. Methyl-10-undecenoate (see structure in Figure 1) was chosen as the reactant because it could be easily produced in our laboratory from 10-undecenoic acid. This fatty acid was commercially available at a reasonable cost, while 9-decenoic acid, the precursor of methyl-9-decenoate was extremely expensive. The analyses of a wide range of reaction products were performed using gas chromatography. A comparison with simulations using the methyl-9-decenoate oxidation model of Herbinet et al. [16] was also presented and possible model improvements were discussed. 


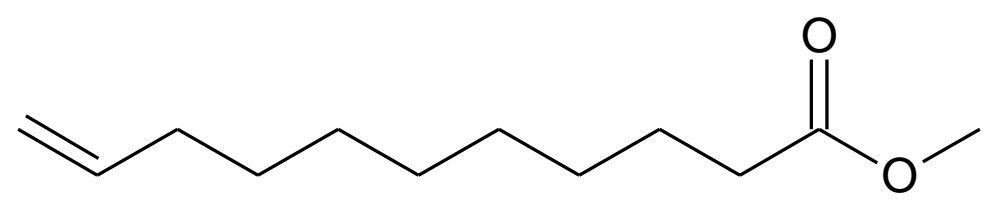

Figure 1: Structure of methyl-10-undecenoate

\section{II/ EXPERIMENTAL METHOD}

According to the procedures proposed by $[18,19,20]$, the methyl-10-undecenoate synthesis was carried out in a laboratory scale batch reactive distillation unit using a Dean-Stark apparatus (see Figure S1 in Supplementary Material). Esterification of 10-undecenoic acid and methanol for yielding methyl-10-undecenoate and water (by product) was performed using sulphuric acid as homogenous catalyst. For shifting the esterification chemical equilibrium in favour of product formation and enhancing thus ester yield, methanol was introduced in excess (alcohol to carboxylic acid molar ratio $=5: 1$ ) while water was removed continuously from the reaction mixture by heterogeneous azeotropic distillation with cyclohexane. The typical used procedure is detailed in Supplementary Material. The analytical grade of the produced methyl-10-undecenoate ( $\geq 98 \mathrm{wt} \%$ ) was checked by GC-FID.

A review by [21] demonstrates that the jet-stirred reactor has been a suitable tool to study the product formation involved during the oxidation of many fuels and biofuels. The design of the spherical fused silica jet-stirred reactor used in the present study was detailed by [22] and is not repeated here. Using this design which includes an annular preheating zone, a perfect gas mixing was obtained with limited concentration and temperature gradients inside the reactive zone. The reactor (volume $=85 \mathrm{~cm}^{3}$ ) was used under isobaric and isothermal conditions. It was heated by means of electrical resistances [16]. 
A scheme of the experimental set-up is shown in Figure S2 in Supplementary Material. During the jet-stirred reactor study, the ester liquid flow was controlled using a liquidCoriolis-flow-controller, a type of controller that does not need fluid specific calibration. This liquid flow was then mixed with helium and passed through an evaporator before oxygen was added prior the reactor inlet. The relative uncertainty in gas flow rates was around $5 \%$. The flows of helium and oxygen (provided by Messer with purities of $99.99 \%$ and $99.999 \%$, respectively) were controlled using thermal flow rate controllers.

At the outlet of the reactor, the gas flow was transferred to two gas chromatographs (GCs) connected on-line via heated transfer lines kept at $448 \mathrm{~K}$ to avoid condensation. The use of a higher temperature is not recommended in order to limit reactions in the transfer lines as a start of reactivity of some species (like aldehydes or ethers) can be observed from temperatures around $473 \mathrm{~K}$. A few millimeters after the connection between the reactor and the transfer lines, the temperature of the effluent from the reactor dropped of several hundreds of $\mathrm{K}$, so that the chemical reactions were considered as frozen.

A first GC was equipped with a thermal conductivity detector and a Carbosphere packed column. It was used to quantify oxygen, carbon oxides and methane. A second GC with a flame-ionization detector preceded by a methanizer and a PlotQ capillary column was used to quantify molecules containing up to five carbon atoms. A third GC including a flameionization detector and a HP-5 capillary column was used for the off-line analysis of molecules containing at least five carbon atoms and collected in a trap located at the reactor outlet and maintained at liquid nitrogen temperature. The content of the trap was injected into the gas chromatograph after warming up to the ambient temperature and addition of solvent (acetone) and a known amount of internal standard (n-octane). Identification was performed thanks to a fourth off-line GC fitted with a Plot Q or a HP-5MS column, and coupled with a 
mass spectrometer. Retention times from the GC-MS chromatogram were then used to identify the species corresponding to the peaks observed in the GC-FID chromatogram obtained under same conditions. Water and hydrogen were not quantified. Response factors were known by injecting commercial calibration mixtures or using the effective carbon number method [23].

The jet-stirred reactor was operated at temperatures from 500 to $1100 \mathrm{~K}$, at atmospheric pressure (800 Torr), at a residence time of $1.5 \mathrm{~s}$, with dilute mixtures at equivalence ratios $(\phi)$ of $0.5,1.0$, and 2.0 in helium. With the analysis method described previously, the carbon atom balance was closed within a deviation about $10 \%$, except for temperatures close to the maximum of low-temperature reactivity for which larger deviations were observed (up to $30 \%$ at $625 \mathrm{~K}$ ), certainly due to the species which could not be quantified, and also to condensation of undetected large oxygenated products in GC transfer lines. All the measured experimental mole fractions are given in a tabular form in Supplementary Material.

\section{III/ FUEL CONSUMPTION AND COMMON COMBUSTION PRODUCT FORMATION}

Figure 2 presents the evolution with temperature of the mole fractions of fuel, oxygen, carbon oxides, and methane for the three studied equivalence ratios (in all the experimental mole fraction profile figures below, error bars are given for an equivalence ratio of 1).

The profile of fuel mole fraction clearly displays a negative temperature coefficient (NTC) zone at equivalence ratios 0.5 and 1.0 , while the reactivity is much lower at temperatures lower than $800 \mathrm{~K}$ at an equivalence ratio of 2.0. As the equivalence ratio decreases, the fuel reactivity is significantly promoted below $800 \mathrm{~K}$, while this promoting effect is gradually 
reduced with increasing temperatures. A decrease of equivalence ratio also enhances the production of carbon oxides, but decreases the production of methane.
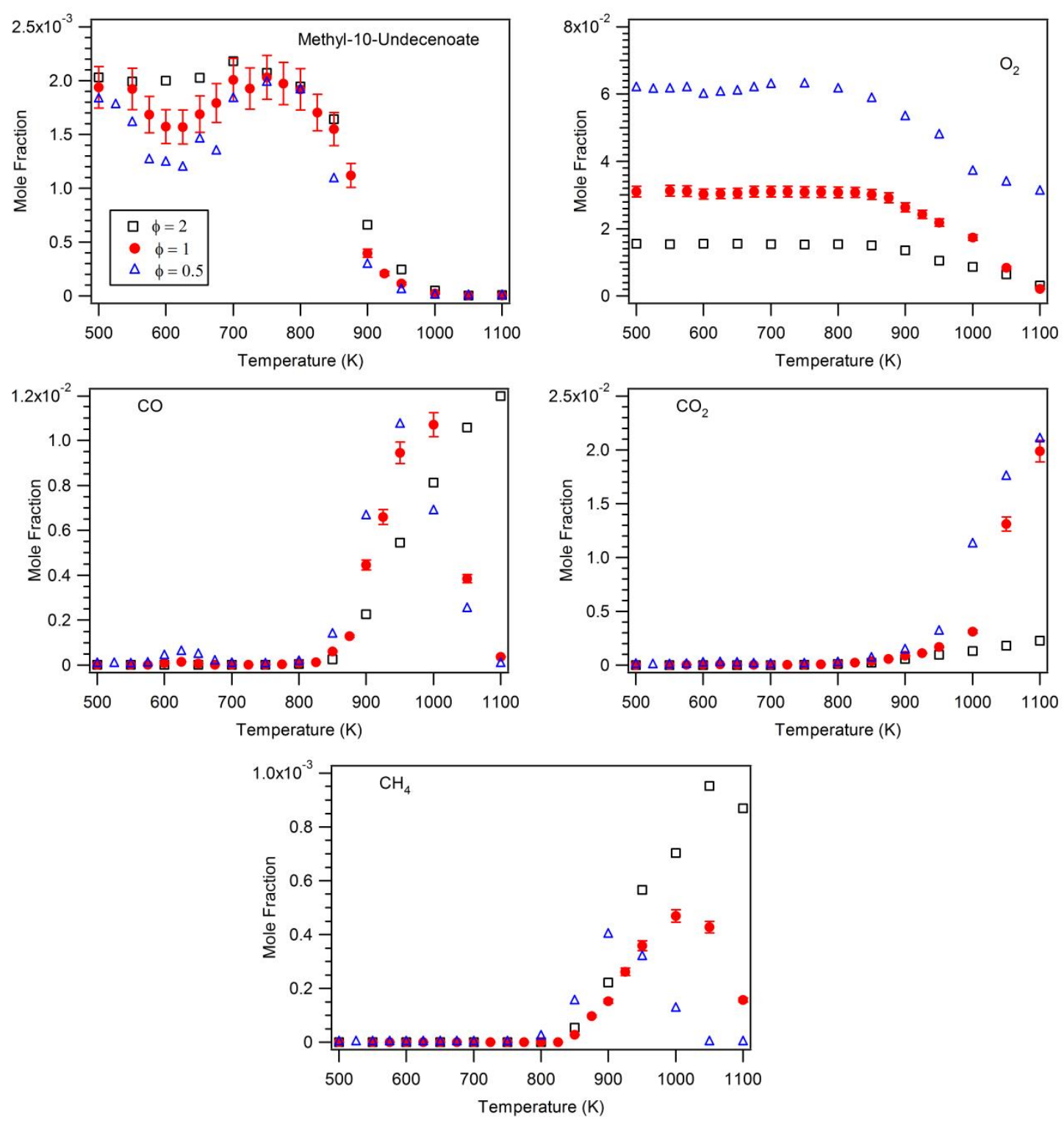

Figure 2: Evolution with temperature of the mole fractions of fuel, oxygen, carbon oxides, and methane.

A comparison, the conclusions of which should be taken with care, has been attempted using the few experimental JSR data existing for other $\mathrm{C}_{10+}$ esters. Figure 3 compares the evolution with temperature of methyl-10-undecenoate conversion at $\phi=1$ with those of the $\mathrm{C}_{11}-\mathrm{C}_{19}$ 
saturated and unsaturated esters which were previously studied under similar conditions according to literature: i.e. methyl decanoate [24], methyl stearate [15] and methyl oleate [15]. The JSR oxidation of a $\mathrm{C}_{11}$ saturated ester, methyl decanoate, was previously studied under the same experimental conditions (same pressure, residence time and same fuel inlet mole fraction) as in the present work [23]. The JSR oxidation of a saturated $\mathrm{C}_{19}$ ester, methyl stearate (methyl octadecanoate) and of an unsaturated $\mathrm{C}_{19}$ ester, methyl oleate (methyl-9octadecenoate), diluted in benzene, was carried out by Rodriguez et al. [15] using a similar reactor at 800 Torr and at a residence time of $2 \mathrm{~s}$ and with an ester inlet mole fraction of 0.0004. Note that under our oxidation conditions, the influence of a $33 \%$ change in the residence time is limited.

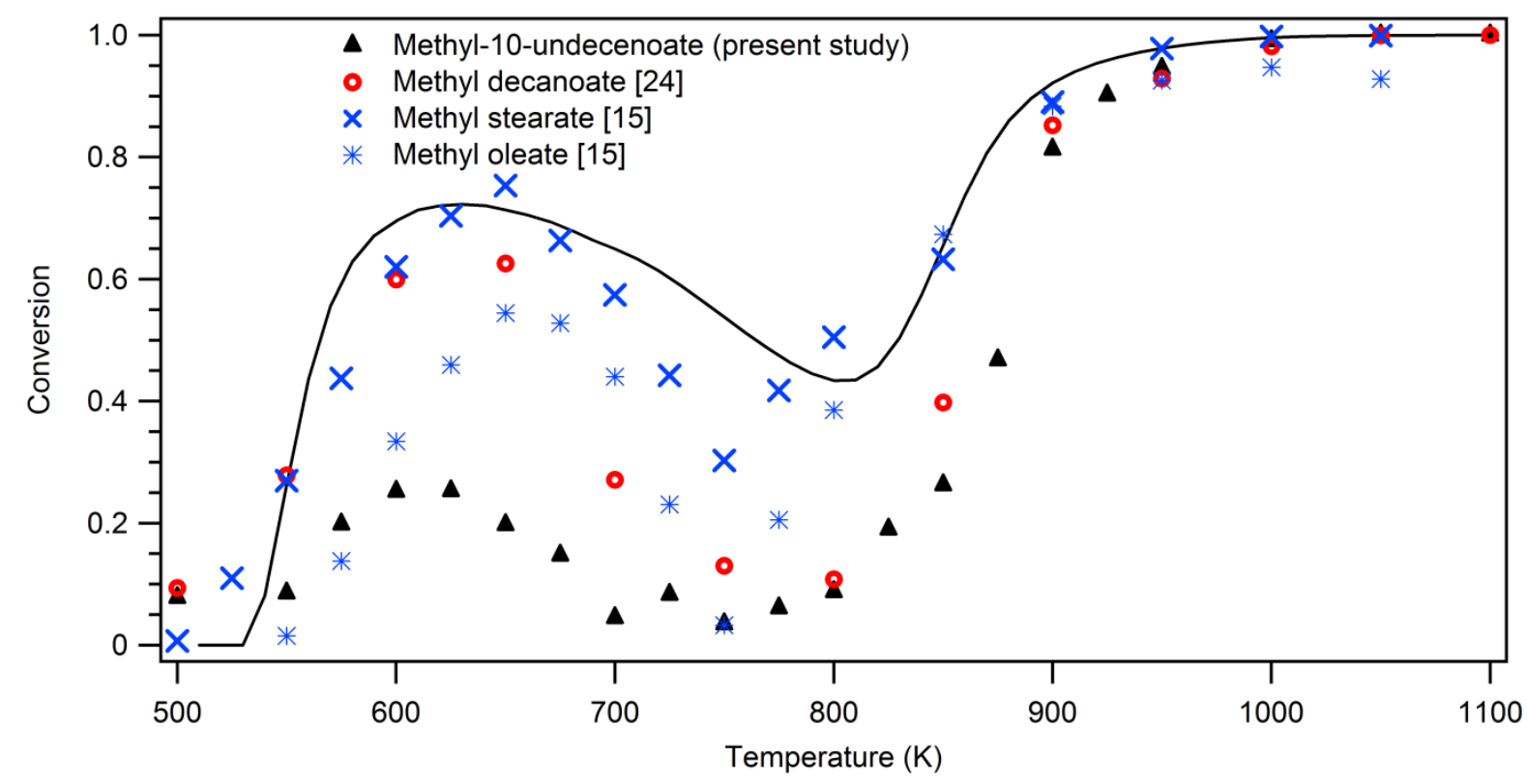

Figure 3: Comparison of the evolution with temperature of methyl-10-undecenoate conversion with those of $\mathrm{C}_{11}-\mathrm{C}_{19}$ saturated and unsaturated esters previously studied in JSR. Symbols are experiments (present study and literature data) and the line corresponds to a simulation of the present experiments using the methyl-9-decenoate model proposed by Herbinet et al. [16] (stoichiometric conditions). 
Figure 3 demonstrates that although the four esters exhibit a close reactivity above $900 \mathrm{~K}$, there are large differences at lower temperatures, especially below $750 \mathrm{~K}$. The difference of reactivity observed between methyl decanoate and methyl-9-undecenoate cannot be explained by the difference of one atom of carbon between both molecules. The experimental study of Biet et al. [25] and the numerical work of Westbrook et al. [26] about the oxidation of large alkanes demonstrated that the difference of reactivity between $n$-decane and $n$-hexadecane was somewhat limited. The difference of reactivity observed in Figure 3 is really due to a specific chemistry involved by the presence of a double bond, much more than to any effect of molecule size. This figure also shows that the difference of reactivity between the saturated and the unsaturated esters is significantly lower for the $\mathrm{C}_{19}$ reactants than for the $\mathrm{C}_{11-12}$ fuels. When the size of a $\mathrm{C}_{10+}$ ester increases, the specific chemistry involved by an unsaturation becomes less important.

Finally, the results of a simulation of the present experiments made using the model proposed by Herbinet et al. [16] is plotted in Figure 3. This figure shows that the model of Herbinet et al. [16], which is the only one found in literature for a molecule with a structure close to that of our reactant, captures globally well the shape of the conversion evolution with temperature. However, this model, which was initially written for an unsaturated ester, is notably better to represent the level of reactivity of methyl decanoate than that of methyl-10-undecenoate. This is because many features of the specific chemistry involved by the presence of a double bond are missing in this model. This is further discussed in this paper. 


\section{IVI FORMATION OF MINOR PRODUCTS AND PROPOSED WAYS OF FORMATION}

In this part, we describe the minor products that were identified and quantified, and we propose pathways of formation specific to the chemistry of unsaturated esters. The analyzed products were hydrocarbons or esters with one aldehyde function, unsaturated and di-unsaturated hydrocarbons, unsaturated and saturated esters, and cyclic ethers. Figure S3 (650 K, stoichiometric condition) in supplementary information shows an example of chromatogram for the species with retention time longer than that of methyl-10-undecenoate. Table S1 in supplementary information shows all the species with at least four atoms of carbon and including an ester function which have been identified during this study. As many species have been detected, with sometimes co-elution and unclear identification, not all of them could be quantified. Figure S4 in Supplementary Material presents a selectivity diagram of the $\mathrm{C}_{2+}$ quantified products.

\section{a/ Products with one aldehyde function}

Saturated and unsaturated aldehydes, which are common products of alkane or alkene oxidation, were detected and quantified in this study. This was also the case of species containing both an ester and a carbonyl functions.

Figure 4 shows the evolution with temperature of the mole fraction of the produced $\mathrm{C}_{1}$ to $\mathrm{C}_{5}$ saturated aldehydes. The leaner the reaction mixture, the more aldehydes were produced, with formaldehyde and acetaldehyde being the most abundant of this type of products. As shown in Figure S4, below $800 \mathrm{~K}$, formaldehyde and acetaldehyde are the two products produced with the largest selectivity apart from carbon monoxide. 

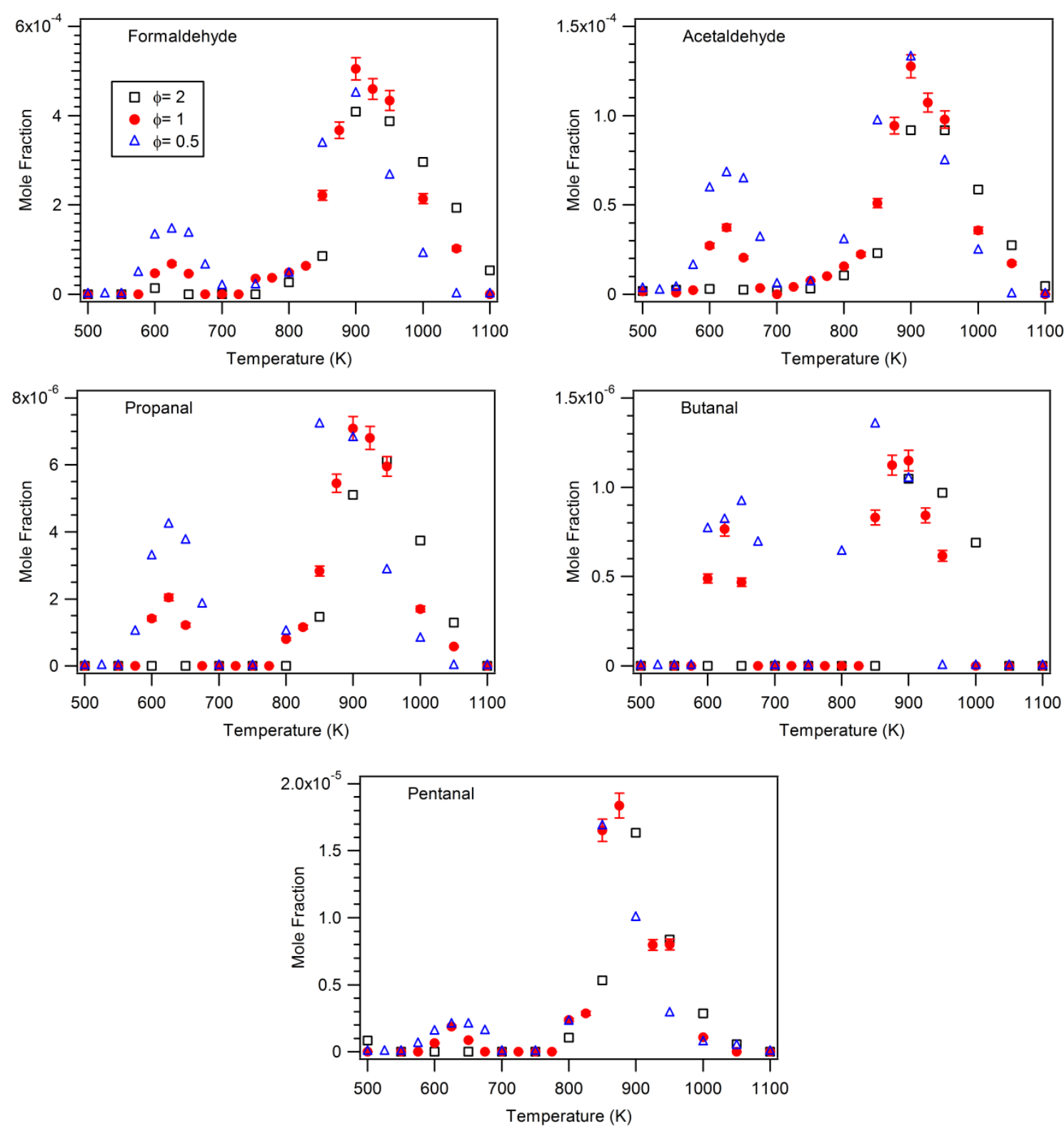

Figure 4: Evolution with temperature of the mole fractions of saturated aldehydes.

Under lean and stoichiometric conditions, the profiles of the 5 observed aldehydes display clearly two zones of formation, one below $750 \mathrm{~K}$ and one above. The low-temperature aldehyde production was significantly more limited for rich mixtures. Even if formaldehyde 
can be formed via the Waddington mechanism as described further in the text, many ways of formation not specific to unsaturated esters can be envisaged for these small aldehydes.

Unsaturated aldehydes are typical products of the reactions of allylic radicals with $\mathrm{HO}_{2}$. Figure 5 shows the evolution with temperature of the mole fractions of the produced $\mathrm{C}_{3}$ to $\mathrm{C}_{4}$ unsaturated aldehydes, as well as that of methyl-11-oxo-9-undecenoate.

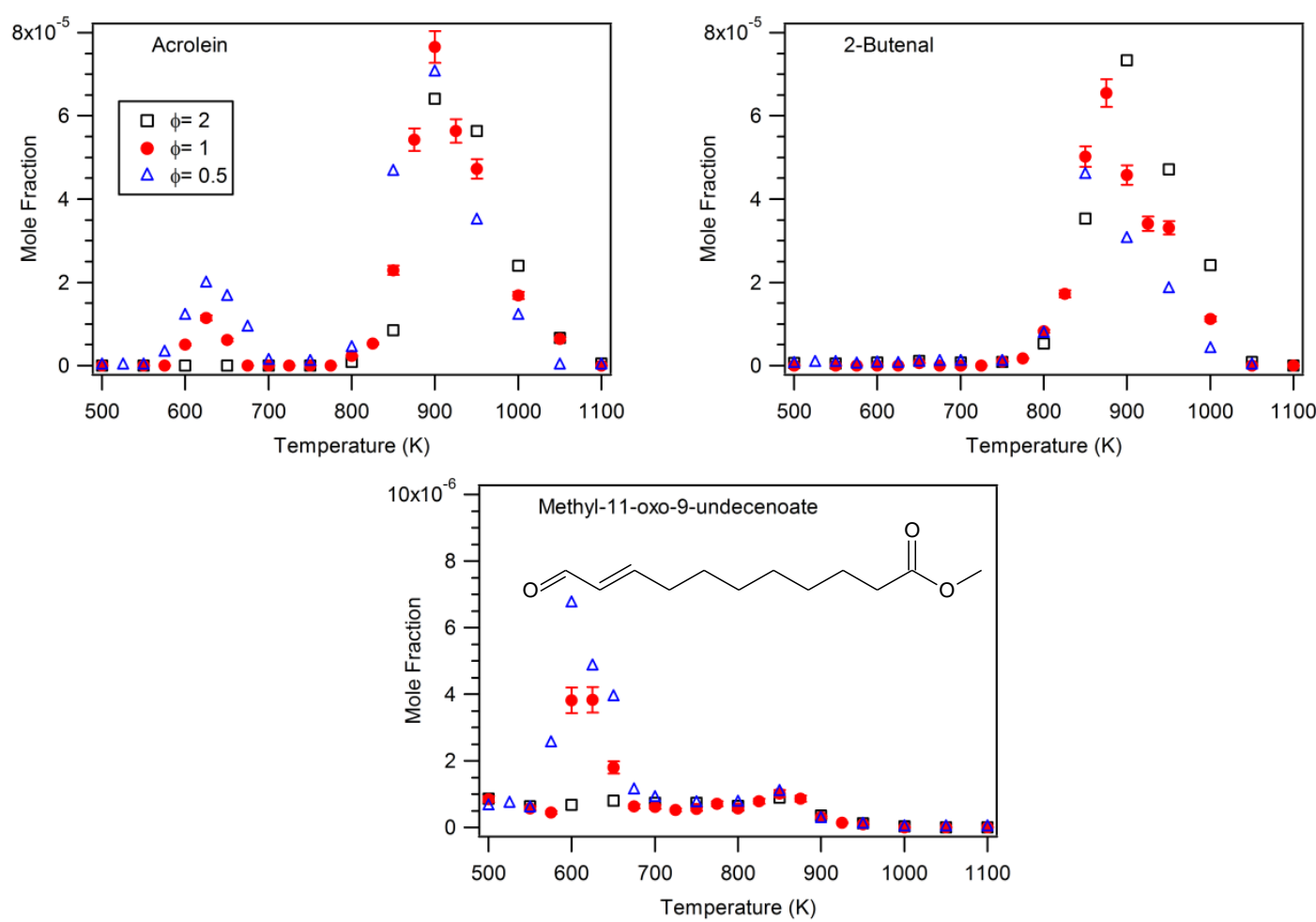

Figure 5: Evolution with temperature of the mole fractions of unsaturated hydrocarbons and esters with an aldehyde function.

The production of methyl-11-oxo-9-undecenoate indicates that the allylic radical obtained from methyl-10-undecenoate reacts with $\mathrm{HO}_{2}$ as in the case of alkenes. This was not considered in the models published for unsaturated ester $[15,16]$. Figure 6 illustrates the possible reaction schemes of the allylic radicals derived from methyl-10-undecenoate with $\mathrm{HO}_{2}$ radicals based on theoretical work of Goldsmith et al. [27], which was recently applied to 
update detailed kinetic mechanisms of alkenes [28, 29]. As is shown in Figure 6, the reactions of allylic radicals obtained from methyl-10-undecenoate with $\mathrm{HO}_{2}$ also contribute to the production of acrolein, a typical toxic non-regulated emission, which was also detected when biodiesel was combusted in diesel engines [10]. As is shown in Figure 5, acrolein was also formed in notable amounts in the present study. However, as acrolein was formed in higher amounts above $800 \mathrm{~K}$ and also in rich mixtures, its formation pathway is not only this shown in Figure 6, but includes also reactions of small species such as the oxidation of allyl radicals. The pathway shown in the left side of Figure 6 could also lead to a $C_{12}$ unsaturated methyl ester with a ketone function via a $\mathrm{C}-\mathrm{H}$ bond scission. However, such products were not easy to identify due to the difficulty of determining the position of double bond relative to the carbonyl function.

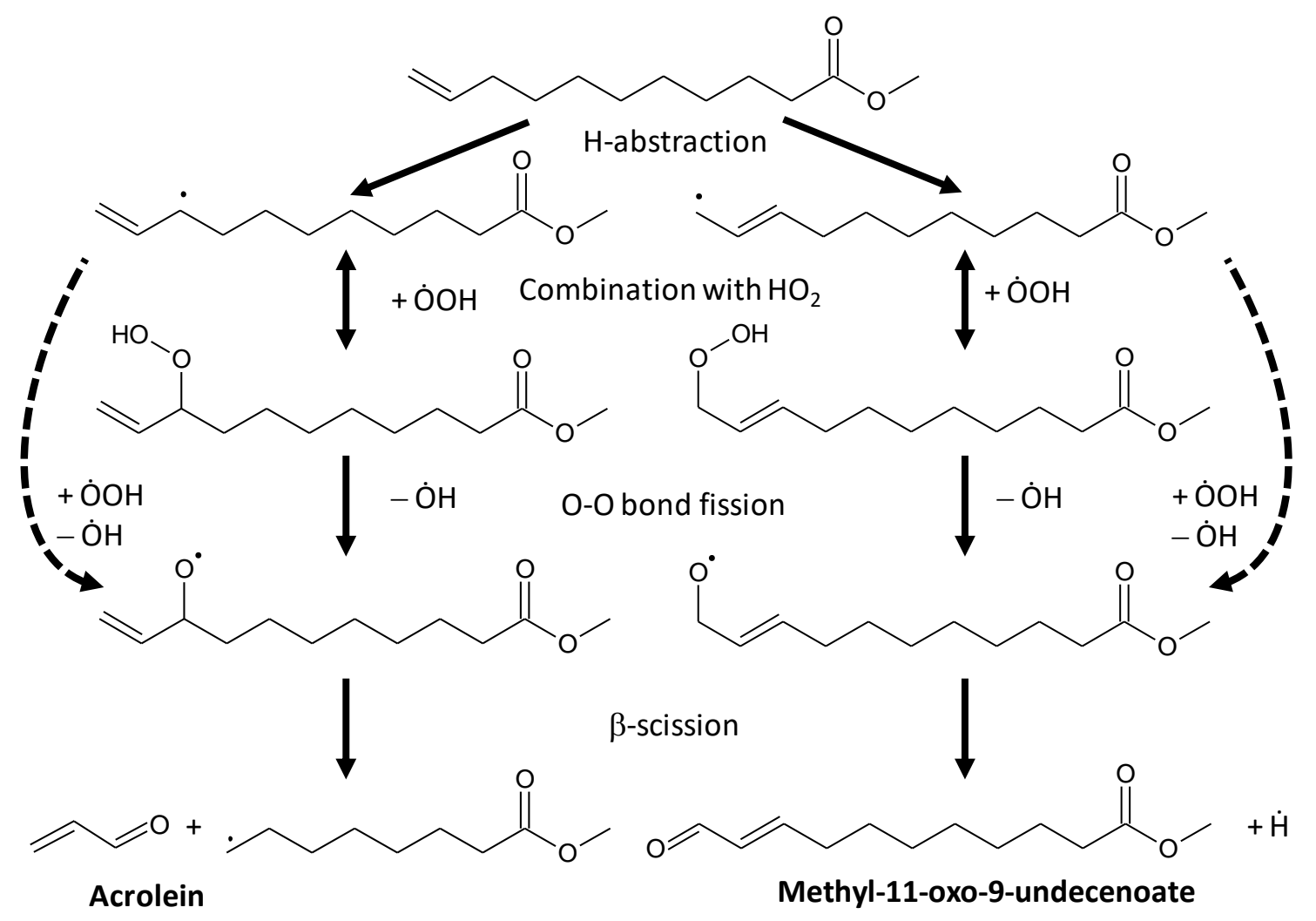

Figure 6: Possible schemes of reactions of the allylic radicals of methyl-10-undecenoate with $\mathrm{HO}_{2}$ radicals. Curved dashed arrows are concerted reactions. 
Figure 7 displays the mole fractions of saturated aldehydes including an ester function. When they are smaller than the initial reactant, these species that are specific to the oxidation of unsaturated esters [15] indicate an important role of reactions via the so-called Waddington mechanism [30]. In agreement with recent studies on alkenes of intermediate size [28], the inhibiting effect of these pathways on the low temperature reactivity of methyl oleate and methyl linoleate were numerically demonstrated by Rodriguez et al. [15].
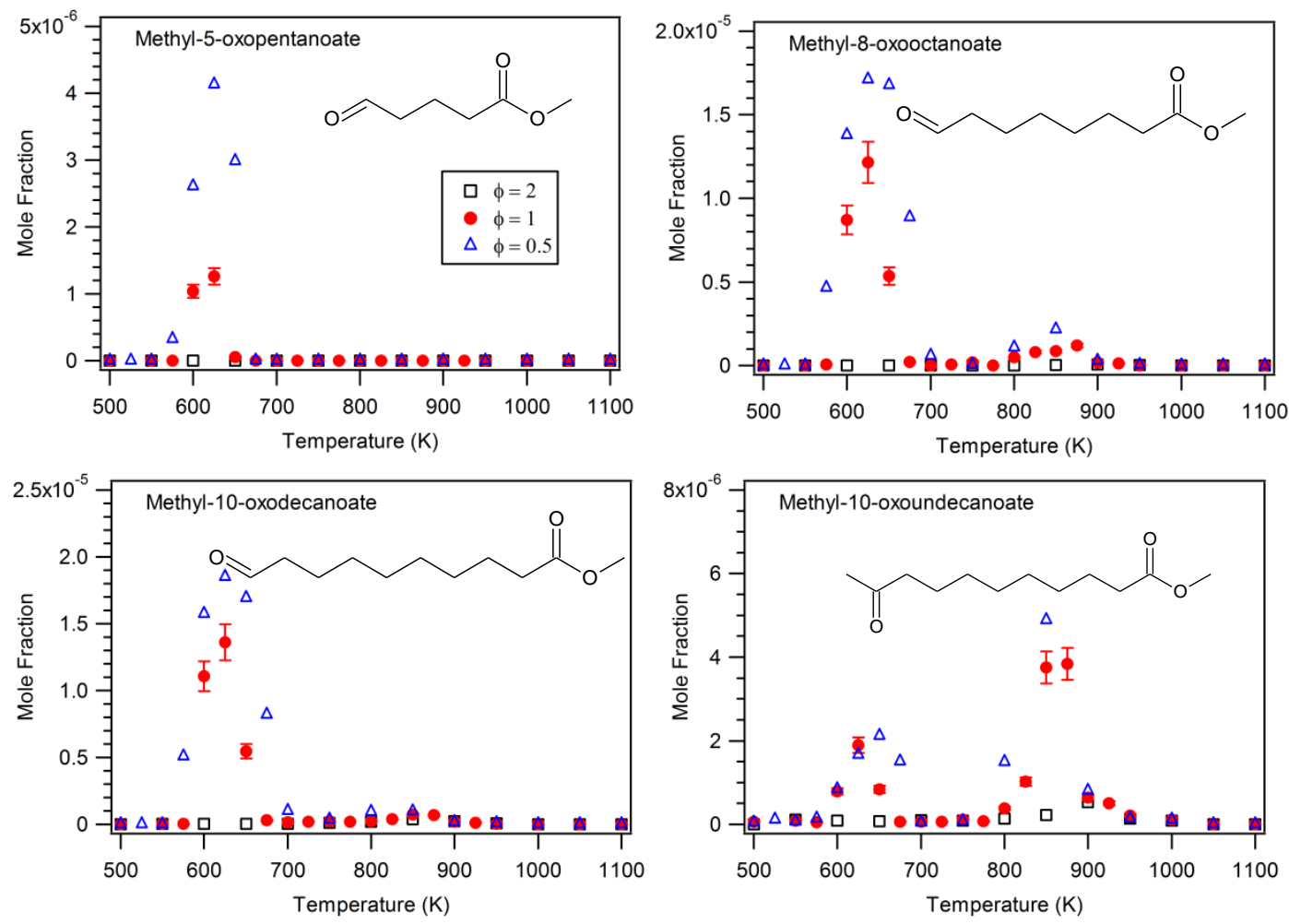

Figure 7: Evolution with temperature of the mole fractions of saturated aldehydes including an ester function.

As shown in Figure 7, three saturated aldehydes including an ester function and smaller than the initial reactant were quantified here. Since the Waddington mechanism starts from the production of an adduct by addition of an $\mathrm{OH}$ radical to a double bond, these species were mainly formed below $750 \mathrm{~K}$. The adduct formation is a reaction with a low activation energy, 
but thermodynamically disfavored when increasing temperature. When starting from methyl10-undecenoate, the reactions via the Waddington mechanism produce formaldehyde and methyl-10-oxodecanoate as illustrated in Figure 8. Under stoichiometric and lean conditions, methyl-10-oxodecanoate has the third largest selectivity amongst $\mathrm{C}_{2+}$ compounds (see Figure S4)

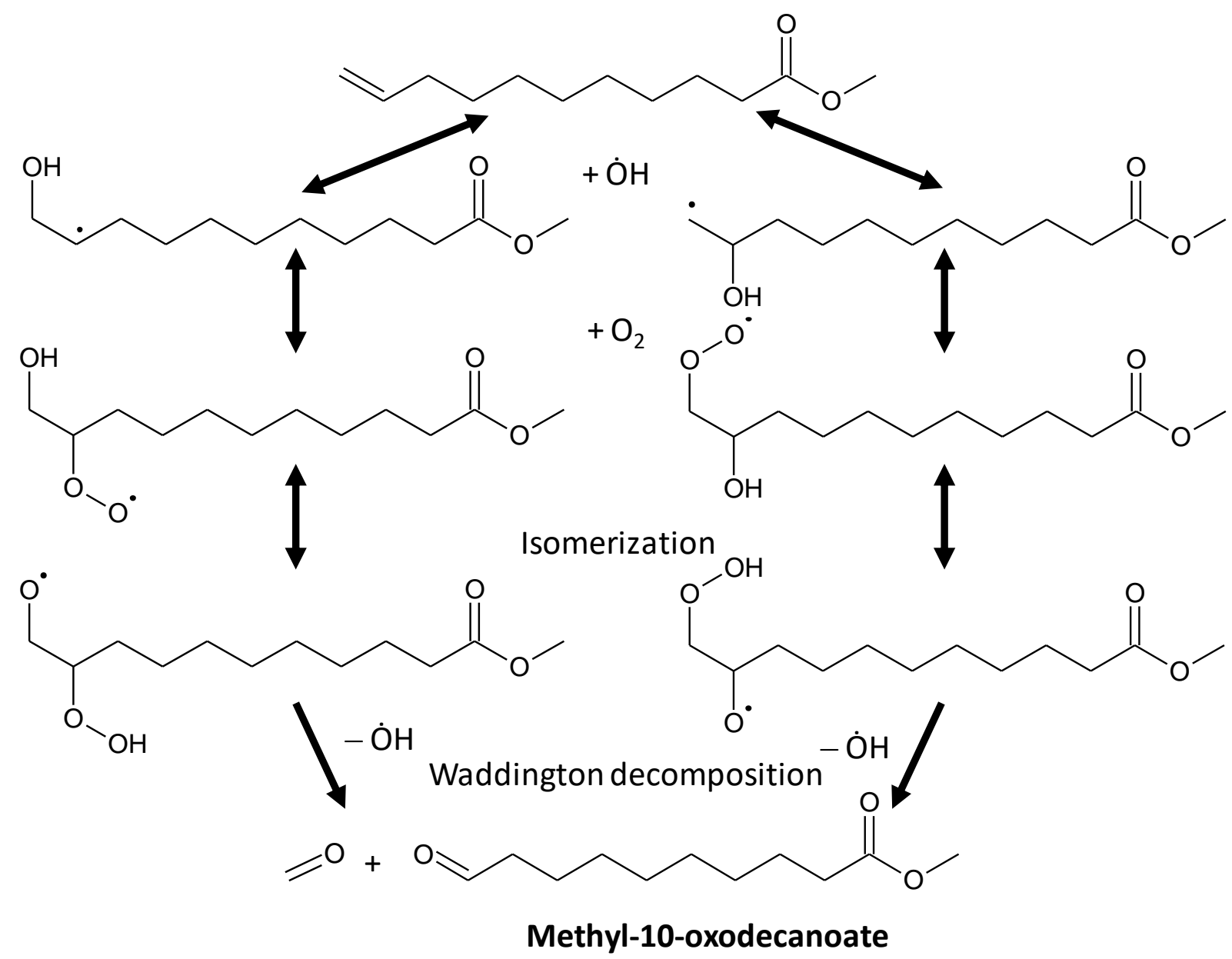

Figure 8: Reactions via Waddington mechanism starting from methyl-10-undecenoate and forming formaldehyde and methyl-10-oxodecanoate.

Similarly, methyl-5-oxopentanoate and methyl-8-oxooctanoate, which are also displayed in Figure 7 , can be produced by reactions via Waddington mechanism from the intermediate species, methyl-6-hexenoate and methyl-8-nonenoate, which are produced during the oxidation of methyl-10-undecenoate as it will be seen further in the text. 
Another interesting product plotted in Figure 7 is methyl-10-oxoundecanoate. This species is most probably obtained as an oxidation product of the $\alpha$-hydroxyalkyl radical. This pathway was recently found significant during a 1-hexene modeling study [28]. As shown in Figure 9, the two adducts obtained by $\mathrm{OH}$ addition to the fuel double bond can go through a two-step isomerization to produce two $\alpha$-hydroxyalkyl radicals (with an ester function), which can be subsequently oxidized to produce methyl-11-oxoundecanoate and methyl-10-oxoundecanoate (detected and quantified during the present experiments). As the rate constant of the $\alpha$ hydroxyalkyl radical oxidation has a very low activation energy [31], methyl-10oxoundecanoate is produced at temperatures both below and above $800 \mathrm{~K}$. As illustrated in Figure 9, methyl-11-oxoundecanoate was also expected to be produced, but it might co-elute with other products, which made it difficult to be identified. Note also that, despite several products deriving from the $\mathrm{OH}$ radical to the double bond were quantified, the formation of enols was not experimentally detected. 


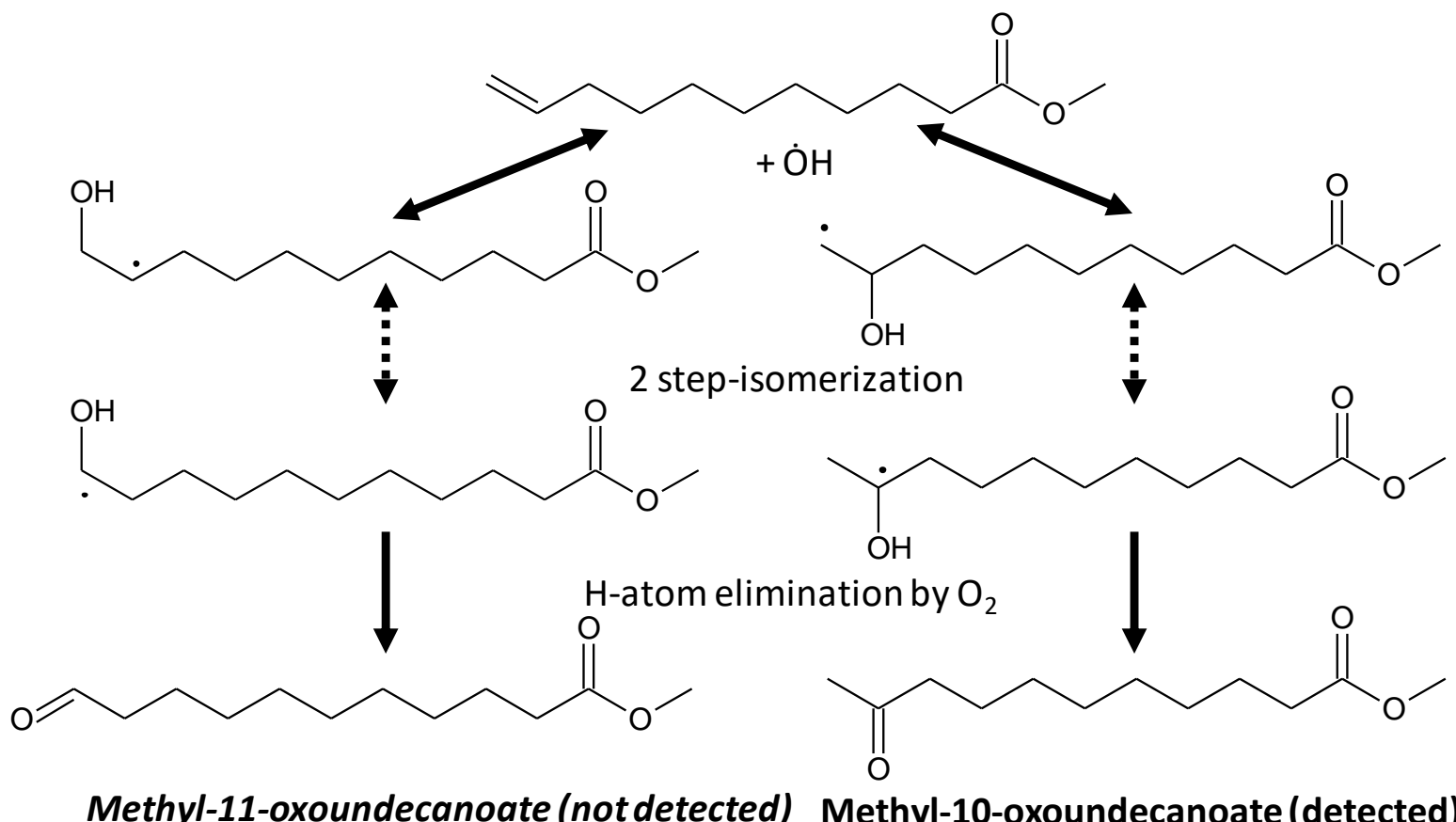

Figure 9: Possible production pathways of methyl-11-oxoundecanoate and methyl-10-

oxoundecanoate. As shown during 1-hexene oxidation modeling [28], the isomerizations from beta to alpha radicals occur via two subsequent isomerizations (dashed arrows).

\section{b/ Unsaturated and di-unsaturated hydrocarbons}

Alkenes were detected and quantified during the present experiments and their mole fraction profiles are displayed in Figure 10. Short chain alkenes such as ethylene, propene and 1-butene were produced abundantly as they can be produced from various pathways not specific to unsaturated esters. During the oxidation of methyl-10-undecenoate, short chain alkenes were formed at temperatures higher than $800 \mathrm{~K}$, and an increase of the equivalence ratio promotes their production. 

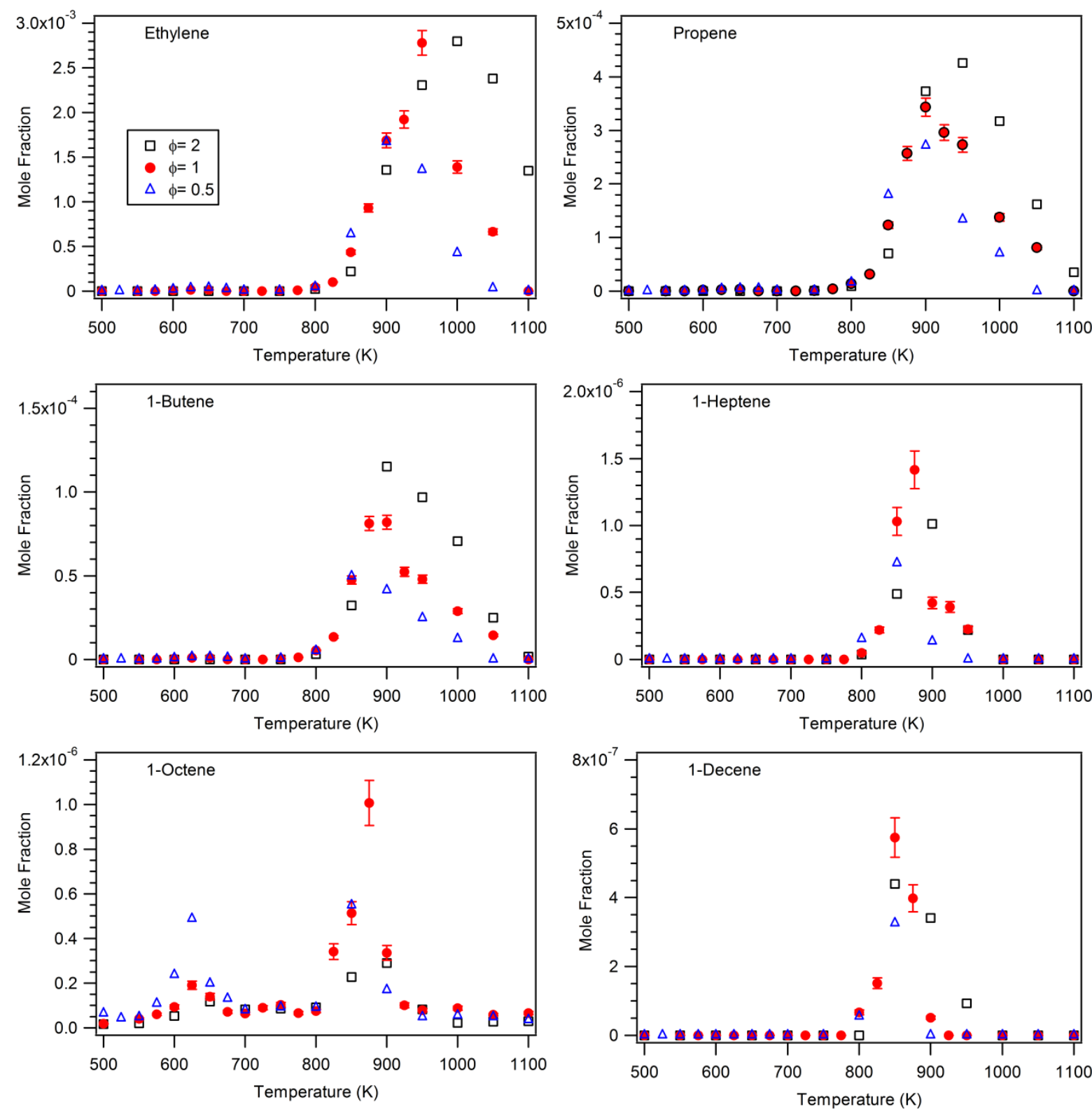

Figure 10: Evolution with temperature of the mole fractions of alkenes.

Longer chain alkenes were produced in much lower amounts (lower than $2 \mathrm{ppm}$ ). The possible reaction pathways forming 1-octene and 1-heptene are shown in Figure 11. The initial reaction is the addition of an $\mathrm{H}$-atom to the double bond, followed by a 7-member ring transition state isomerization. The resulted $\mathrm{C}_{12} \mathrm{H}_{23} \mathrm{O}_{2}$ ester radicals can either form alkenes or unsaturated methyl esters via $\beta$-scissions. $\mathrm{C}_{12} \mathrm{H}_{23} \mathrm{O}_{2}$ ester radicals can also be formed via a most favored 6-member ring transition state isomerization and be a source of 
methyl-7-octenoate (see Figure 14) and of 1-hexene which could not be quantified due to a strong co-elution with methyl-2-propenoate (see Figure 14). The $\mathrm{C}_{12} \mathrm{H}_{23} \mathrm{O}_{2}$ radical producing 1-decene is yielded via at least two-step isomerizations of the two adducts of $\mathrm{H}$-atom addition, which may explain the much lower production of 1-decene.

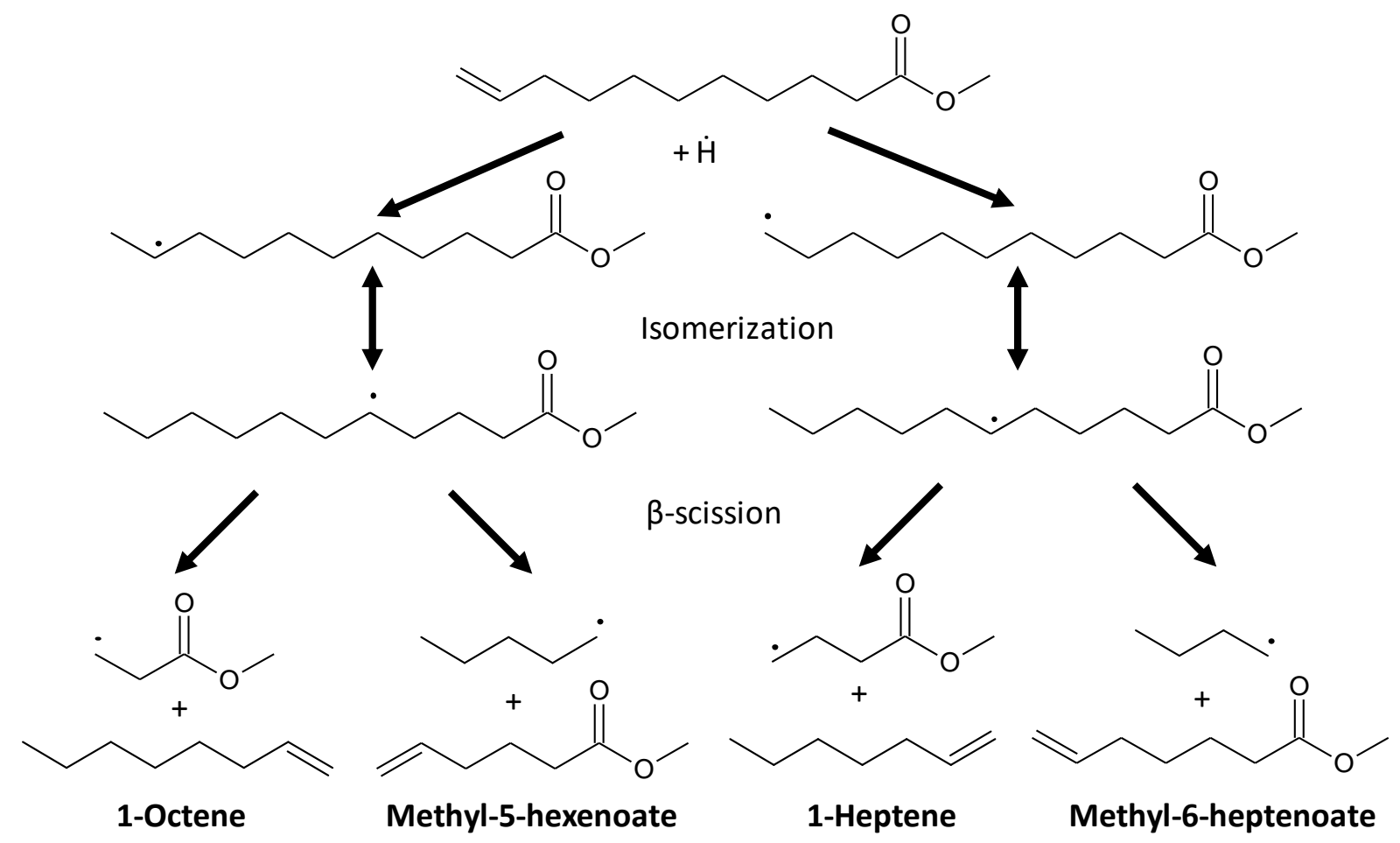

Figure 11: Possible pathways leading to the formation of 1-octene and 1-heptene.

Figure 12 shows the evolution with temperature of the mole fraction of the produced dienes. In the same way as for the oxidation of alkenes [28], dienes are primarily produced at temperatures higher than $800 \mathrm{~K}$, where $\beta$-scissions are favored. As 1,3-butadiene can be produced through $\beta$-scissions of various radicals with a double bond, it is the most abundant diene produced. 

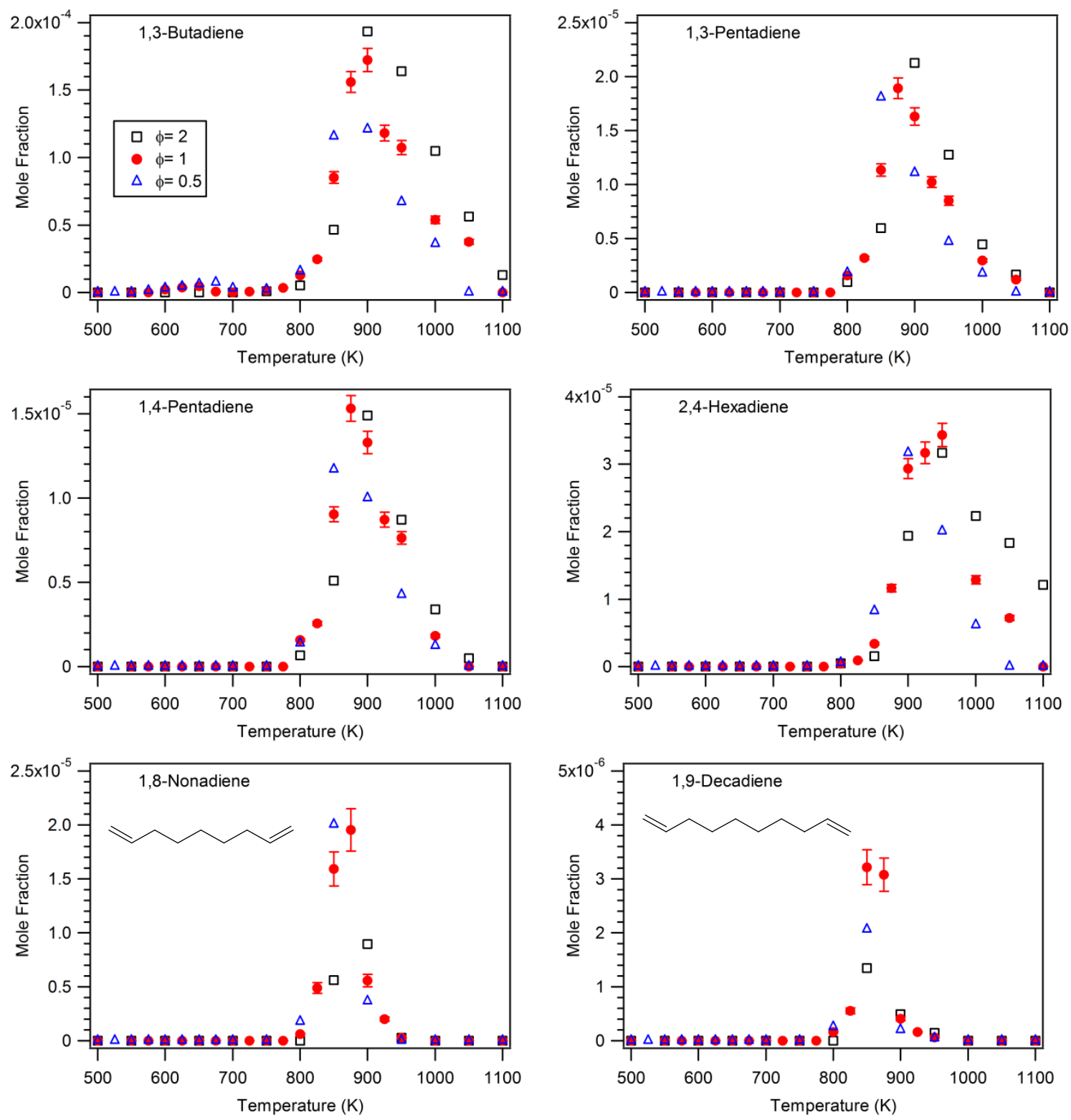

Figure 12: Evolution with temperature of the mole fractions of dienes.

The species more specific to methyl-10-undecenoate oxidation are 1,8-nonadiene and 1,9-decadiene. The possible pathways which can be envisaged for their production are shown in Figure 13. These two dienes can both be produced via the $\beta$-scissions of radicals derived from fuel. According to the theoretical work of Oyeyemi et al. [32], the $\mathrm{C}-\mathrm{C}$ bond in beta to the ester function has a bond dissociation energy $(81.6 \mathrm{kcal} / \mathrm{mol})$ lower than that of the $\mathrm{C}-\mathrm{C}$ 
bond in alpha to the ester function $(93.6 \mathrm{kcal} / \mathrm{mol})$ by more than $10 \mathrm{kcal} / \mathrm{mol}$. This explains why the maximum mole fraction of 1,8-nonadiene is larger by a factor of around 8 than that 1,9-decadiene as is shown in Figure 12. The bond dissociation energy of a C-C bond in gamma or further position $(86.8 \mathrm{kcal} / \mathrm{mol})$ is about $5 \mathrm{kcal} / \mathrm{mol}$ higher than in beta position. This could be the reason why the formation of 1,7-octadiene and 1,6-heptadiene has not been observed.

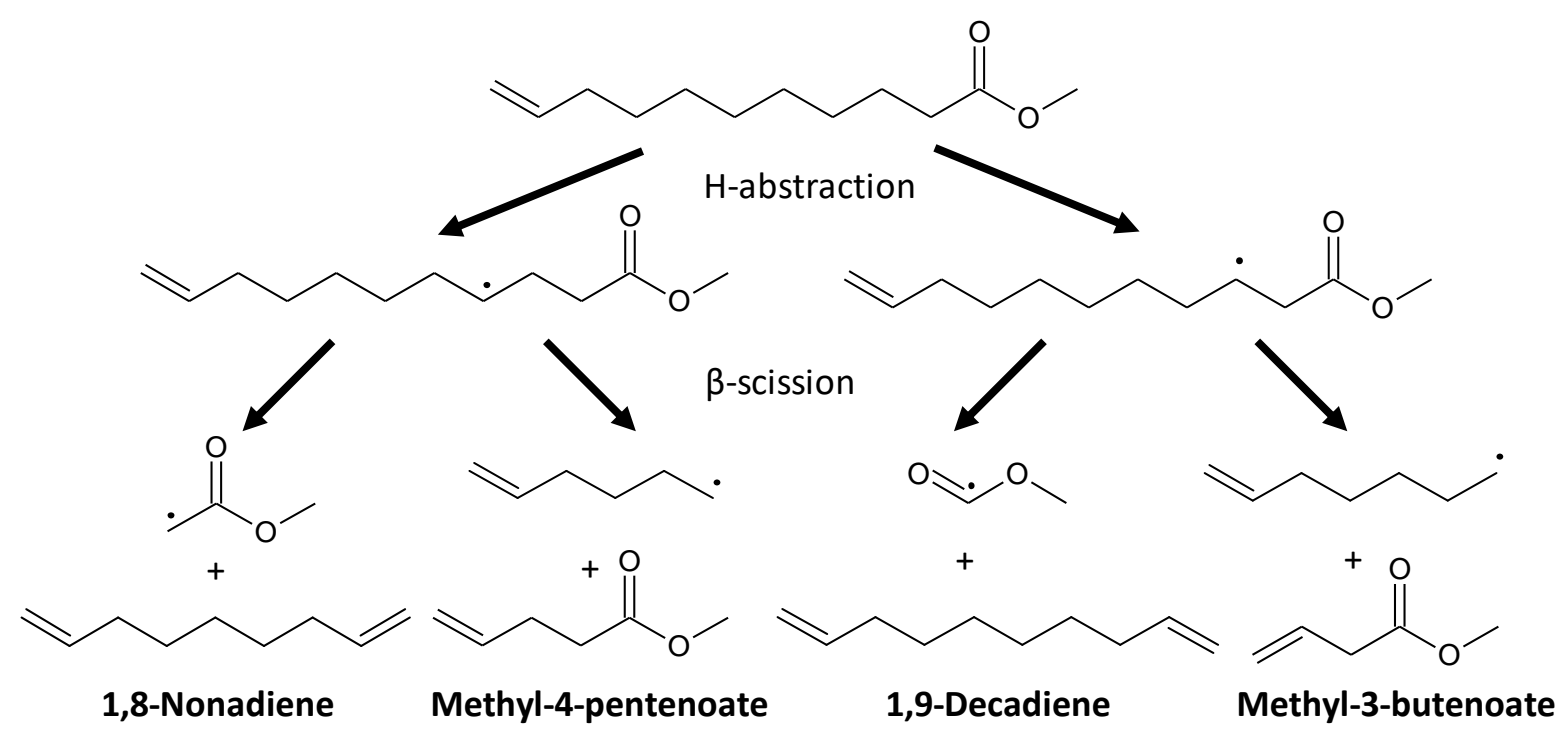

Figure 13: Possible pathways leading to the formation of 1,8-nonadiene and 1,9-decadiene.

\section{c/ Unsaturated and saturated esters}

A series of unsaturated methyl esters from methyl-2-propenoate to methyl-9-decenoate were detected and quantified during the oxidation of methyl-10-undecenoate. The evolution with temperature of their mole fractions is presented in Figure 14, methyl-2-propenoate is the most abundant product, followed by methyl-3-butenoate, methyl-5-hexenoate and methyl-7octenoate. Methyl-4-pentenoate is formed is smaller amount because of the competition with the favored decomposition yielding 1,8-nonadiene (see Figure 13). As is previously shown in Figures 11 and 13, unsaturated esters can be produced via $\beta$-scissions. In addition, the retroene reaction may also contribute to the production of unsaturated esters. 

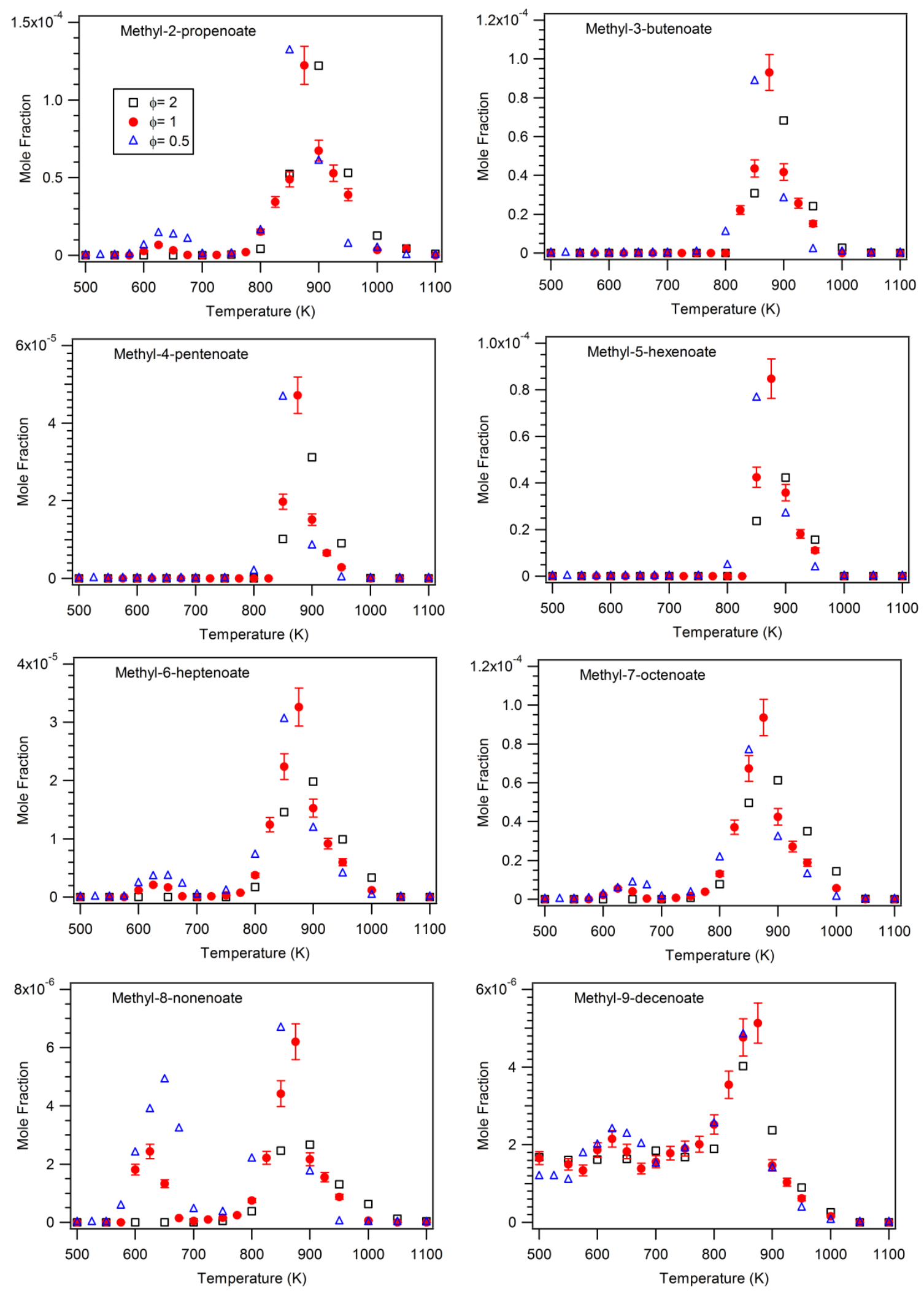

Figure 14: Evolution with temperature of the mole fractions of unsaturated methyl esters. 
The modeling work of Rodriguez et al. [15] showed these decomposition reactions to be important pathways during unsaturated esters oxidation above $750 \mathrm{~K}$. As is shown in Figure 15 , in case of methyl-10-undecenoate, the retro-ene reaction products are methyl-7-octenoate and propene. This explains the relative large abundance of methyl-7-octenoate.

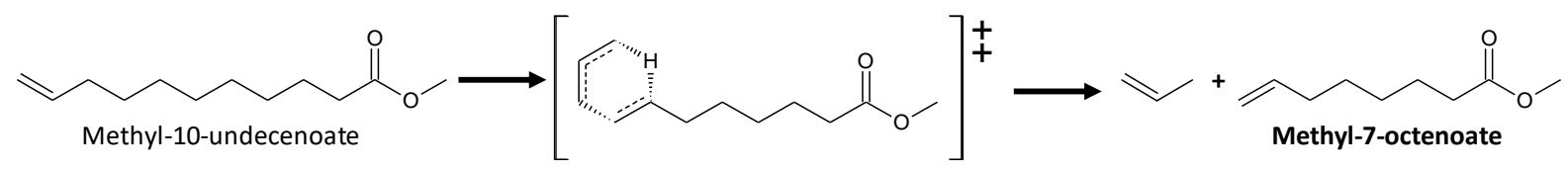

Figure 15: Retro-ene reactions in the case of methyl-10-undecenoate.

Two species, potentially identified by GC-MS as saturated esters, were also quantified during these experiments; they were typically produced at temperatures below $800 \mathrm{~K}$, as is shown in Figure 16. Traces of methyl decanoate were also detected. The reaction pathways leading to these saturated esters need yet to be more investigated, since alkanes are not usual products of alkene oxidation [28].
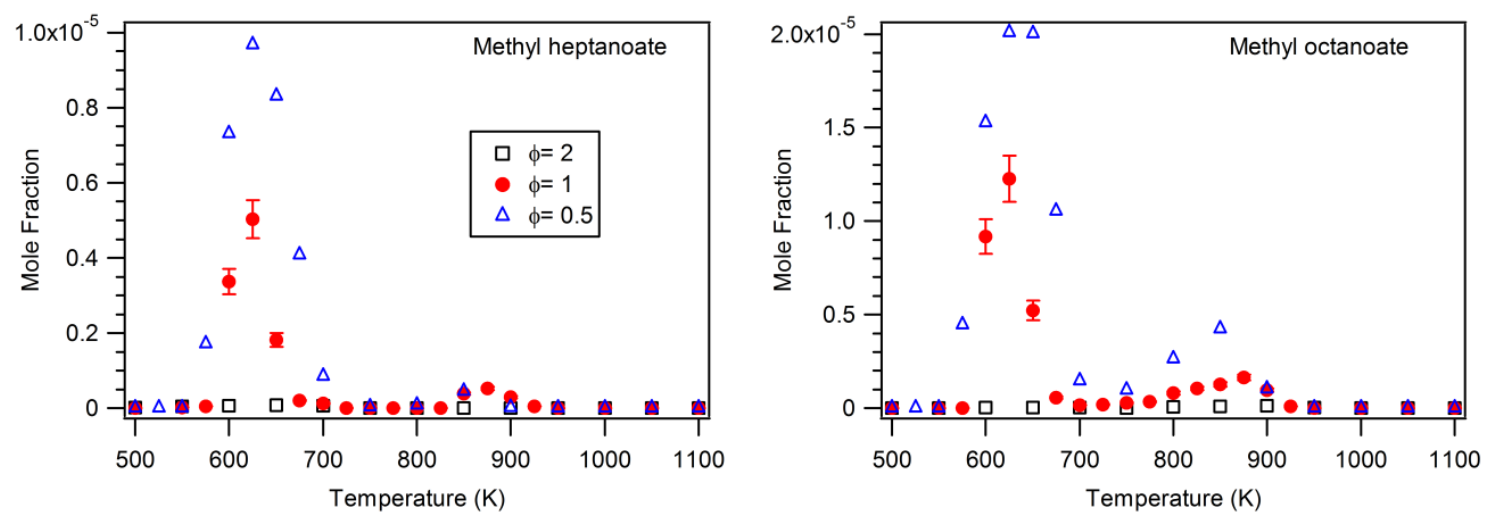

Figure 16: Evolution with temperature of the mole fractions of saturated methyl esters.

\section{d/ Cyclic ethers with an ester function}

While cyclic ethers are very common and abundant products of the oxidation of alkanes [33] and saturated esters [24], there were more rarely reported in the case of alkenes [28] and still 
less in the case of unsaturated esters [14]. As shown in Table S1 in supplementary information, 10 cyclic ethers with an ester function were detected in this study, but only five of them could be quantified.

In the same way as alkenes can react with $\mathrm{HO}_{2}$ radicals to form oxiranes [28] by direct epoxidation, oxiranes with an ester function are expected to be produced during the oxidation of methyl-10-undecenoate. As is shown in Figure 17, methyl-9-(oxiran-2-yl)nonanoate, the reaction product of methyl-10-undecenoate with $\mathrm{HO}_{2}$ radicals, was detected and quantified.

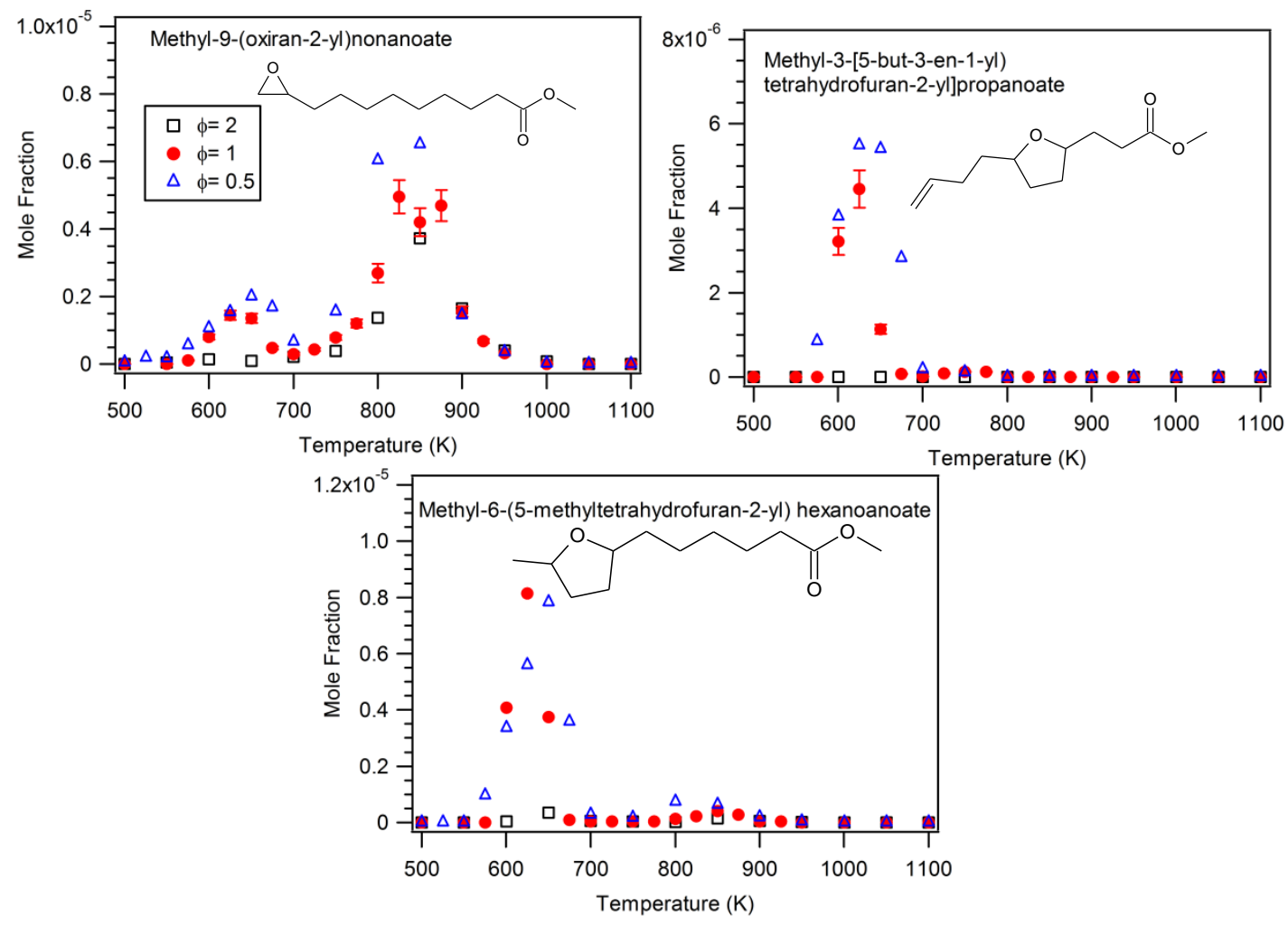

Figure 17: Evolution with temperature of the mole fractions of the cyclic ethers quantified in this study.

At low temperatures, the radicals obtained by $\mathrm{H}$-abstractions from fuel react mainly by addition to $\mathrm{O}_{2}$ forming $\mathrm{ROO}$ radicals. These $\mathrm{ROO}$ radicals can isomerize to QOOH radicals, of which the reaction via a 7-member ring transition state is the most favored [33]. Therefore, the QOOH radicals mainly lead to the formation of 5-membered ring cyclic ethers. Figure 17 
also presents the mole fractions of the two 5-membered ring cyclic ethers which were quantified in this study. The amount of the 5-membered ring cyclic ether with a double bond is relatively lower than that of the saturated one, the possible formation pathways of which are presented in Figure 18. Note that the pathway in the right side of Figure 18 which starts by an isomerization via 5 or 6-membered ring transition state is probably less favored than the pathway in the left side. The a priori surprising importance of reactions starting by H-atom additions was also pointed out in the 1-hexene study [28]. Some other 5-membered ring cyclic ethers with a double bond were also detected during the experiment (see Table S1), but most of them were present in low amount and co-eluted with some other products, which made it hard to quantify them accurately.

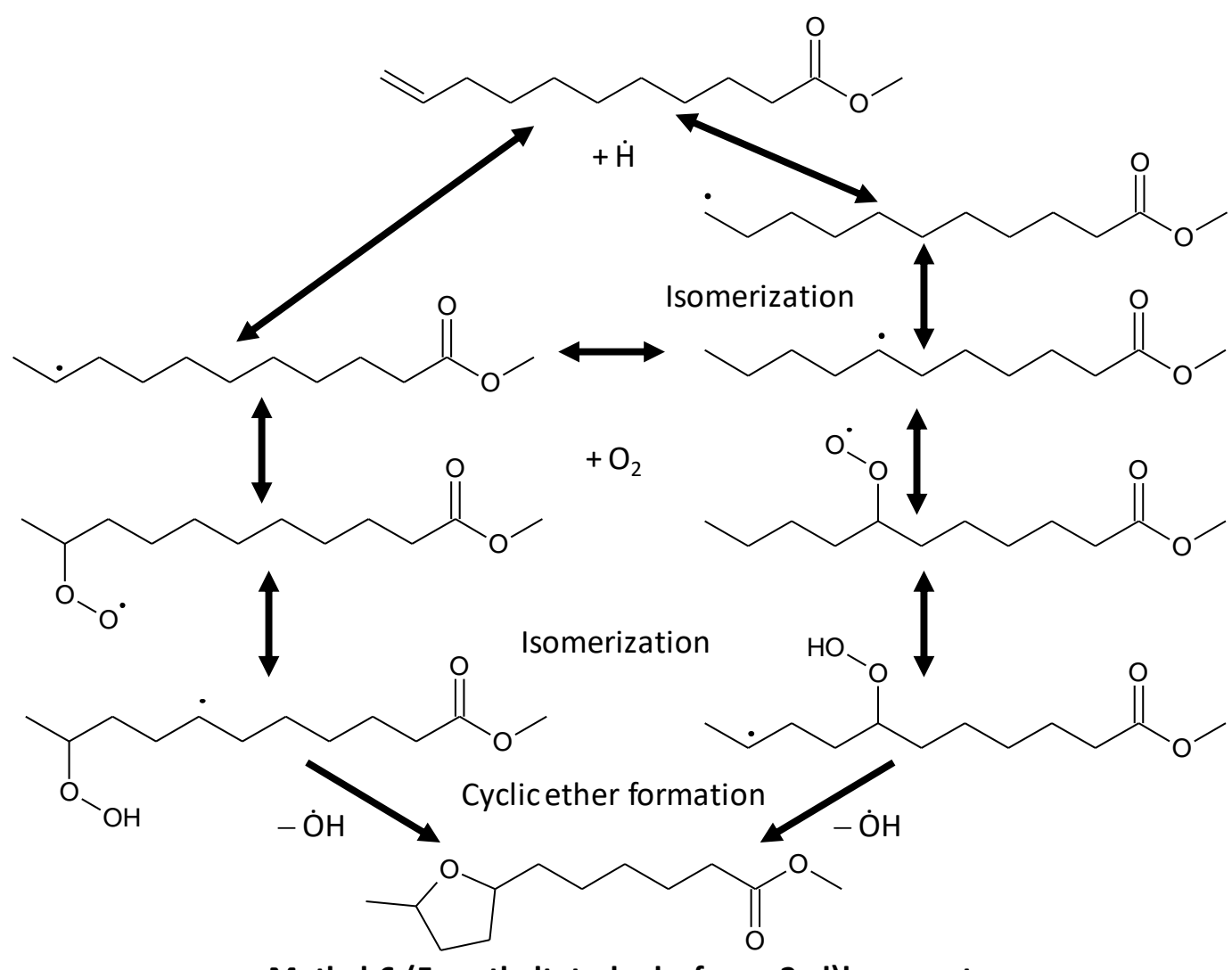

Methyl-6-(5-methyltetrahydrofuran-2-yl)hexanoate

Figure 18: Possible reaction pathways for the formation of methyl-6-(5methyltetrahydrofuran-2-yl)hexanoate. 
The formation of hydroxycyclic ethers is a concurrent reaction channel to the Waddington mechanism, and hydroxycyclic ethers have been recently experimentally detected and quantified in the low temperature oxidation studies of alkenes [28]. As shown in Figure 19, methyl-6-[5-(hydroxymethyl)tetrahydrofuran-2-yl]hexanoate and methyl-7-[4-(hydroxyl methyl)oxetan-2-yl] heptanoate were detected and quantified in this study.
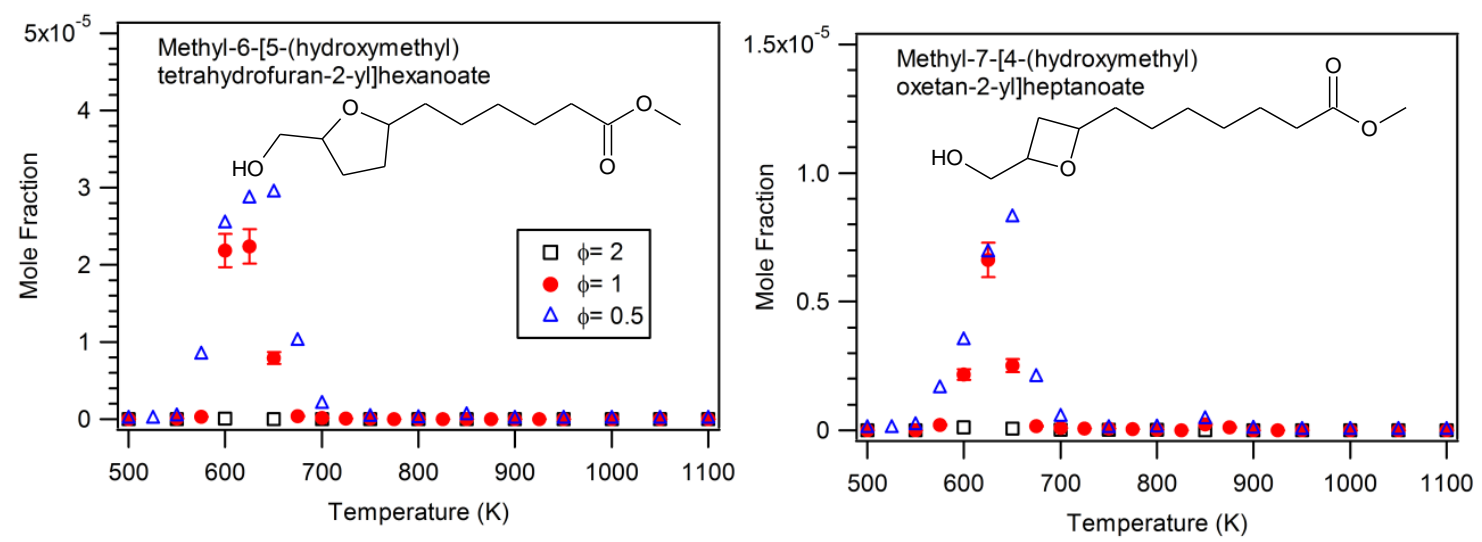

Figure 19: Evolution with temperature of the mole fractions of the hydroxyl cyclic ethers quantified in this study.

As the 5-membered ring ether is more easily formed, the produced mole fraction of this ether was larger than that of methyl-7-[4-(hydroxymethyl) oxetan-2-yl. The formation pathways of methyl-6-[5-(hydroxymethyl)tetrahydrofuran-2-yl]hexanoate is described in Figure 20, in which the hydroxyl radical adds first to the terminal carbon of the double bond, followed by an addition to oxygen, the subsequent isomerization, and finally the formation of 2-propyl,5hydroxymethyl-tetrahydrofuran via cyclization. Under stoichiometric and lean conditions, the selectivity of this 5-membered ring hydroxycyclic ether is the third largest one amongst $\mathrm{C}_{2+}$ compounds (see Figure S4), just after those of carbon monoxide and $\mathrm{C}_{1}-\mathrm{C}_{2}$ aldehydes. This high selectivity indicates that the reactions of formation of hydroxycyclic ethers should be 
considered in a comprehensive kinetic mechanism of the oxidation of biodiesel fuel or of their surrogates.

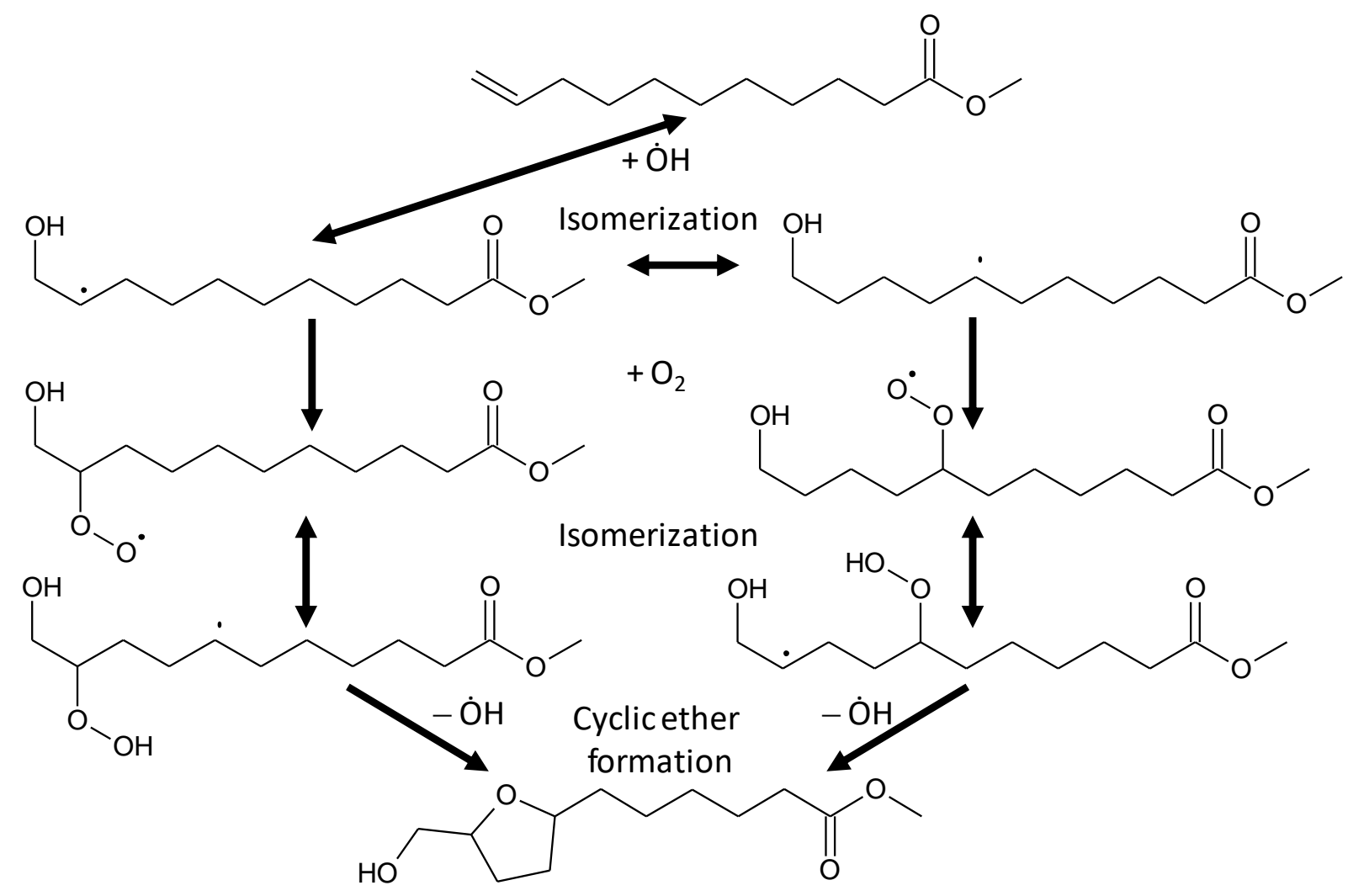

Methyl-6-[5-(hydroxymethyl) tetrahydrofuran-2-yl]hexanoate

Figure 20: Possible reaction pathways for the formation of methyl-6-[5-(hydroxymethyl) tetrahydrofuran-2-yl]hexanoate.

\section{V/ DISCUSSION ABOUT POSSIBLE MODEL IMPROVEMENTS}

The first and only published model for an intermediate size unsaturated ester was developed in 2010 in Livermore by Herbinet et al. [16]. This model lacked of validation as experimental data about unsaturated ester were very scarce at that time. Since then significant progress in 
the understanding of the modeling of alkene oxidation has been made as described in the papers by Mehl et al. [34] and Meng et al. [28]. These should be considered when a new model for the oxidation of such compounds would be developed.

When comparing the flow rate analyses made at $650 \mathrm{~K}$ for methyl-9-decenoate presented in 2010 by Herbinet et al. [16] with those made at the same temperature for 1-hexene by Meng et al. [28] in 2017, it can be seen that the flow rates towards $\mathrm{H}$ and $\mathrm{OH}$ radical additions are lower with the old model $(11.3 \%)$ than with the new one $(46.6 \%)$. This is due to newly considered rate constants, such as those proposed by Zádor et al. for $\mathrm{OH}$ reactions with alkenes [35]. Consequently, the flow rates towards H-abstractions are larger even when considering the difference due to the larger alkyl chain. Using sensitivity analyses, Meng et al. [28] showed that the largest promoting effect on the reactivity was observed for the abstraction of allylic $\mathrm{H}$-atoms by $\mathrm{OH}$ radicals. The observed difference in flow rates as is above described can then partly explain the too large reactivity predicted by the model of Herbinet et al. [16].

Another reason for this lower reactivity can be found in fact that the model of Herbinet et al. [16] used the same rate rules for the isomerizations involving alkenes as for alkanes. The fact that the isomerizations of alkenyl and alkenyl peroxy radicals involving a transition state including a double bond are significantly hindered, as was proposed by Bounaceur et al. [36], was not considered by Herbinet et al. [16]. This rate rule difference notably increases the reactivity of alkenyl radicals and then also partly accounts for the too large reactivity simulated by the model of Herbinet et al. [16].

There are also two other points that need to be pointed out. These points affect less reactivity, but influence the product distribution. In the model of Herbinet et al. [16], all the adducts produced by $\mathrm{OH}$ radical addition were consumed via the Waddington mechanism, while in the work of Meng et al. [28], these adducts were also a way towards ketohydroperoxides and 
cyclic ethers bearing an alcohol function via oxygen addition. A proof of the existence of this channel in the case of unsaturated esters is given in Figure 19 where notable mole fractions of hydroxyl cyclic ethers are shown. This pathway was shown by Meng et al. [28] to have some promoting effect on the reactivity.

Finally, the reactions of allylic radicals with $\mathrm{HO}_{2}$ radicals, as was proposed in 2011 by Goldsmith et al. [27], were not considered in the model of Herbinet et al. [16]. As shown by the large formation of acrolein and methyl-oxo-9-undecenoate which can be observed in Figure 5, this channel should certainly not be omitted.

\section{VI/ CONCLUSION}

To facilitate the cleaner burning of biodiesel, more experimental and numerical work is needed in order to understand and reduce the formation of toxic products during the use of these renewable fuels in engines. The present paper summarizes experimental results obtained during the jet-stirred oxidation of a neat intermediate size surrogate of biodiesel, methyl-10undecenoate. While the only related published model [16] does not predict this, the unsaturated ester exhibits a much lower reactivity than a saturated ester of close size [24] under the same experimental conditions. This is due to the many missing reactions specific to the chemistry of unsaturated esters, which were put in evidence by the numerous products, especially the oxygenated ones, which were quantified in the present study. If a new model should be developed for the oxidation of intermediate size surrogate of biodiesel, the recent improvement proposed for alkene oxidation should be taken into account.

\section{ACNOWLEDGEMENTS}

Xiangzan Meng would like to acknowledge the financial support from the program of China Scholarship Council (NO. 201506250038). 


\section{REFERENCES}

1. Knothe, G.; Razon, L.F. Prog Energ Combust Sci 2017, 58, 36-59.

2. Campbell, M. F.; Davidson, D. F.; Hanson, R. K.; Westbrook, C. K. Proc Combust Inst 2013, $34(1), 419-425$.

3. Wang, W.; Gowdagiri, S.; Oehlschlaeger, M. A. Combust Flame 2014, 161 (12), 3014-3021.

4. Das, D. D.; McEnally, C. S.; Pfefferle, L. D. Combust Flame 2015, 162 (4), 14891497.

5. Sarathy, S. M.; Gaïl, S.; Syed, S. A.; Thomson, M. J.; Dagaut, P. Proc Combust Inst 2007, 31 (1), 1015-1022.

6. Yang, B.; Westbrook, C. K.; Cool, T. A.; Hansen, N.; Kohse-Höinghaus, K. Proc Combust Inst 2013, 34 (1), 443-451.

7. Zhang, K.; Togbé, C.; Dayma, G.; Dagaut, P. Combust Flame 2014, 161 (3), 818-825.

8. Fridlyand, A.; Goldsborough, S.S.; Brezinsky, K. J Phys Chem A 2015, 119, 75597577.

9. Feng, Q.; Wang, Y. L.; Tsotsis, T. T.; Egolfopoulos, F. N. Ind Eng Chem Res 2012, $51(29), 9719-9732$.

10. Lapuerta, M.; Armas, O.; Rodríguez-Fernández, J. Prog Energ Combust Sci 2008, 34 (2), 198-223.

11. Dagaut, P.; Gaïl, S.; Sahasrabudhe, M. Proc Combust Inst 2007, 31 (2), 2955-2961.

12. Dagaut, P.; Gaïl, S. J Phys Chem A 2007, 111 (19), 3992-4000.

13. Ramirez, H. P.; Hadj-Ali, K.; Diévart, P.; Dayma, G.; Togbé, C.; Moréac, G.; Dagaut, P. Proc Combust Inst 2011, 33 (1), 375-382.

14. Bax, S.; Hakka, M. H.; Glaude, P. A.; Herbinet, O.; Battin-Leclerc, F. Combust Flame 2010, 157 (6), 1220-1229. 
15. Rodriguez, A.; Herbinet, O.; Battin-Leclerc, F.; Frassoldati, A.; Faravelli, T.; Ranzi, E. Combust Flame 2016, 164, 346-362.

16. Herbinet, O.; Pitz, W. J.; Westbrook, C. K. Combust Flame 2010, 157 (5), 893-908.

17. Luo, Z.; Plomer, M.; Lu, T.; Som, S.; Longman, D. E.; Sarathy, S. M.; Pitz, W. J. Fuel 2012, 99, 143-153.

18. Suryawanshi, M.A.; Mane, V.B.; Kumbhar, G.B. JoRSTEM, 2016, 264-268.

19. Harmsen, G.J. Chem. Eng. Process, 2007, 46, 274-280.

20. Neumann, K.; Werth, K.; Martín, A.; Górak, A. Chem. Eng. Res. Design 2016, 107, $52-62$.

21. Herbinet, O.; Battin-Leclerc, F. Int J Chem Kin 2014, 46 (10), 619-639.

22. Herbinet, O.; Dayma, G. Jet-stirred reactors, in: Battin-Leclerc, F. ; Simmie, J.M.; Blurock E. (Eds.), Cleaner Combustion, Springer London, 2013, pp. 183-210.

23. Tranchant, J. Chromatographie en phase gazeuse; Ed. Techniques Ingénieur (1996).

24. Glaude, P. A.; Herbinet, O.; Bax, S.; Biet, J.; Warth, V.; Battin-Leclerc, F. Combust Flame 2010, 157 (11), 2035-2050.

25. Biet, J.; Hakka, M. H.; Warth, V.; Glaude, P.-A.; Battin-Leclerc, F. Energy Fuels 2008, 22 (4), 2258-2269.

26. Westbrook, C. K.; Pitz, W. J.; Herbinet, O.; Curran, H. J.; Silke, E. J. Combust Flame 2009, $156(1), 181-199$.

27. Goldsmith, C. F.; Klippenstein, S. J.; Green, W. H. Proc Combust Inst 2011, 33 (1), 273-282.

28. Meng, X.; Rodriguez, A.; Herbinet, O.; Wang, T., Battin-Leclerc, F. Combust Flame, 181 (2017) 283-299.

29. Zhou, C.-W.; Li, Y.; O’Connor, E.; Somers, K. P.; Thion, S.; Keesee, C.; Mathieu, O.; Petersen, E. L.; DeVerter, T. A.; Oehlschlaeger, M. A.; Kukkadapu, G.; Sung, C.-J.; 
Alrefae, M.; Khaled, F.; Farooq, A.; Dirrenberger, P.; Glaude, P.-A.; Battin-Leclerc, F.; Santner, J.; Ju, Y.; Held, T.; Haas, F. M.; Dryer, F. L.; Curran, H. J. Combust. Flame 2016, 167, 353-379.

30. Stark, M.S.; Waddington, D.J. Int J Chem Kinet 1995, 27, 123-151.

31. Da Silva, G.; Bozzelli, J.W.; Liang, L.; Farrell, J.T. J Phys Chem A, 2009, 113, 89238933.

32. Oyeyemi, V. B.; Keith, J. A.; Carter, E. A. J Phys Chem A 2014, 118 (35), 73927403.

33. Herbinet, O.; Bax, S.; Glaude, P.-A.; Carré, V.; Battin-Leclerc, F. Fuel 2011, 90 (2), $528-535$

34. Mehl, M.; Pitz, W. J.; Westbrook, C. K.; Yasunaga, K.; Conroy, C.; Curran, H.J. Proc. Combust. Inst. 2011, 33, 201-208.

35. Zádor, J.; Jasper, A.W.; Miller, J.A. Phys. Chem. Chem. Phys. 2009, 11, 1104011053.

36. Bounaceur, R.; Warth, V.; Sirjean, B.; Glaude, P.; Fournet, R.; Battinleclerc, F. Proc. Combust. Inst. 2009, 32, 387-394. 